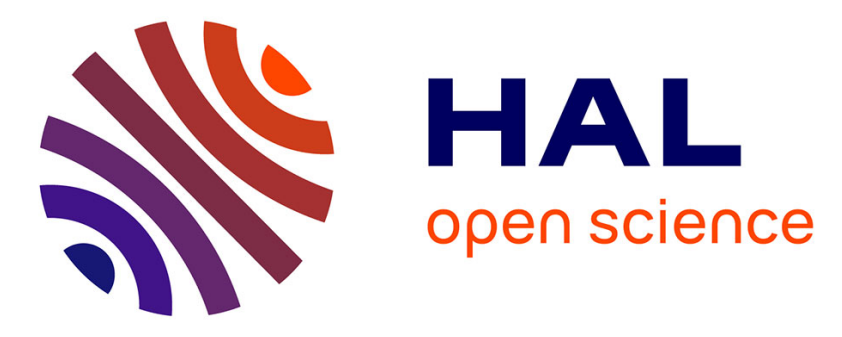

\title{
Deoxynivalenol exposure assessment in a cohort of pregnant women from Bradford, UK
}

Sarah Hepworth, Laura Hardie, Lorna Fraser, Victoria J Burley, Renee Mijal, Christopher Wild, Rafaq Azad, Patricia Mckinney, Paul C Turner

\section{- To cite this version:}

Sarah Hepworth, Laura Hardie, Lorna Fraser, Victoria J Burley, Renee Mijal, et al.. Deoxynivalenol exposure assessment in a cohort of pregnant women from Bradford, UK. Food Additives and Contaminants, 2011, 10.1080/19440049.2010.551301 . hal-00683845

\section{HAL Id: hal-00683845 https://hal.science/hal-00683845}

Submitted on 30 Mar 2012

HAL is a multi-disciplinary open access archive for the deposit and dissemination of scientific research documents, whether they are published or not. The documents may come from teaching and research institutions in France or abroad, or from public or private research centers.
L'archive ouverte pluridisciplinaire HAL, est destinée au dépôt et à la diffusion de documents scientifiques de niveau recherche, publiés ou non, émanant des établissements d'enseignement et de recherche français ou étrangers, des laboratoires publics ou privés. 


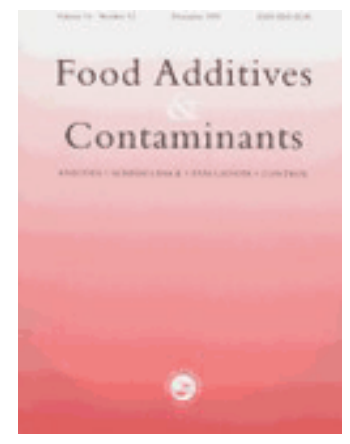

\section{Deoxynivalenol exposure assessment in a cohort of pregnant women from Bradford, UK}

\begin{tabular}{|r|l|}
\hline Journal: & Food Additives and Contaminants \\
\hline Manuscript ID: & TFAC-2010-347.R1 \\
\hline Manuscript Type: & Special Issue \\
\hline Author: & $29-$ Nov-2010 \\
\hline Complete List of Authors: & $\begin{array}{l}\text { Hepworth, Sarah; University of Leeds, Division of Epidemiology } \\
\text { Hardie, Laura; University of Leeds, Division of Epidemiology } \\
\text { Fraser, Lorna; University of Leeds, Division of Epidemiology } \\
\text { Burley, Victoria; University of Leeds, Division of Epidemiology; } \\
\text { Nutritional Epidemiology Unit, Leeds Institute of Genetics, Health } \\
\text { and Therapeutics, University of Leeds, Medicine and Health } \\
\text { Mijal, Renee; Michigan State University, Epidemiology } \\
\text { Wild, Christopher; Iarc } \\
\text { Azad, Rafaq; Bradford Royal Infirmary } \\
\text { McKinney, Patricia; University of Leeds, Division of Epidemiology } \\
\text { Turner, Paul; University of Leeds, Medicine and Health }\end{array}$ \\
\hline Methods/Techniques: & Exposure assessment, LC/MS \\
\hline Additives/Contaminants: & Mycotoxins - trichothecenes \\
\hline Food Types: & Cereals \\
\hline & \\
\hline
\end{tabular}

\section{SCHOLARONE" Manuscripts}




\title{
Deoxynivalenol exposure assessment in a cohort of pregnant women from Bradford, UK
}

\author{
Sarah J Hepworth ${ }^{1}$, Laura J Hardie ${ }^{1}$, Lorna K Fraser ${ }^{1}$, Victoria J. Burley ${ }^{1}$, Renee S. Mijal ${ }^{2}$, \\ Christopher P Wild ${ }^{3}$, Rafaq Azad ${ }^{4}$, Patricia A McKinney ${ }^{1}$, Paul C Turner ${ }^{1 *}$ \\ ${ }^{1}$ Division of Epidemiology, Leeds Institute of Genetics, Health and Therapeutics, \\ University of Leeds, UK. ${ }^{2}$ Department of Epidemiology, Michigan State University, East \\ Lansing, MI, USA. ${ }^{3}$ IARC, Lyon, France, ${ }^{4}$ Department of Clinical Biochemistry, Bradford \\ Royal Infirmary, Bradford, UK.
}

\section{* Corresponding author}

Dr Paul C. Turner

Molecular Epidemiology Group

Leeds Institute of Genetics, Health and Therapeutics,

LIGHT laboratories, Clarendon Way

University of Leeds

Leeds, UK

LS2 9JT

Tel: $\quad 44-113-343-7770$

Fax: 44-113-343-6603

Email :p.c.turner@leeds.ac.uk

\section{Running title \\ Deoxynivalenol exposure during pregnancy}

No competing interests declared 


\begin{abstract}
Abbreviations
$\mathrm{Cl}$ - confidence intervals, DOM-1 - deepoxy-deoxynivalenol, DON-deoxynivalenol, FFQ food frequency questionnaire, FSA - Food Standard Agency, IGF, insulin like growth factor, IS - internal standard, LC-MS - liquid chromatography-mass spectrometry, QC - quality control, TDI - tolerable daily intake
\end{abstract}




\begin{abstract}
Deoxynivalenol (DON) is a ubiquitous contaminant of cereal crops in temperate regions of the world. DON causes growth faltering and immune suppression in animals. Limited information is available on DON exposure in UK sub-populations. The objective of this study was to provide DON exposure assessment in a subset of pregnant women scheduled for an elective caesarean in a large multi-ethnic mother/infant birth cohort from Bradford, UK. Women aged 16-44 years $(n=85)$ provided a urine sample for DON analysis in the last trimester of pregnancy, and concurrently completed a food frequency questionnaire (FFQ). The urinary DON biomarker was detected in all measured samples (geometric mean (GM): 10.3ng DON/mg creatinine, range: $0.5,116.7 \mathrm{ng} / \mathrm{mg}$ ). Levels were higher in women classified as South Asian in origin (GM: $15.2 \mathrm{ng} / \mathrm{mg} ; 95 \% \mathrm{Cl}: 10.7,21.5 \mathrm{ng} / \mathrm{mg}$ ) compared to non South Asians (GM 8.6ng/mg; 95\%Cl: 6.6, 11.8ng/mg), $\mathrm{p}=0.02$ ). Estimated DON intake from FFQ data and typical levels of DON contamination of food suggest that this was mainly due to higher levels of exposure from bread, particularly daily intake of DON from chapattis in South Asians (estimated mean $2.4 \mu \mathrm{g} /$ day; $95 \% \mathrm{Cl}: 1.2,3.7 \mu \mathrm{g} /$ day) compared to non South Asians (estimated mean $0.2 \mu \mathrm{g} / \mathrm{day} ; 95 \% \mathrm{Cl}: 0,0.4 \mu \mathrm{g} / \mathrm{day}$ ), $\mathrm{p}<0.001$. This is the first biomarker demonstration of DON exposure in pregnant women, and several urinary DON levels were the highest ever recorded in any study. A larger survey within this birth cohort is warranted to investigate any potential risk to mothers and their babies, from DON exposure during pregnancy.
\end{abstract}

Keywords:- biomarker, deoxynivalenol, diet, ethnicity, mycotoxin, pregnancy, urine. 


\section{Introduction}

Mycotoxins are frequent contaminants of cereal crops throughout the world (CAST 2003). They are low molecular weight secondary metabolites of a range of fungal species; and those of particular concern for human and animal health include the aflatoxins, fumonisins, deoxynivalenol (DON), ochratoxin and zearalenone (Miller 1995). The most frequently encountered mycotoxin in more temperate regions of the world is the Fusarium mycotoxin, DON. DON contaminates wheat, maize and barley, and due to its stability during processing (Jackson and Bullerman 1999), exposure is predicted to be frequent (SCOOP 2003). In animals consumption of DON contaminated feed leads to acute gastrointestinal toxicity characterized by rapid onset, nausea, vomiting, abdominal pain, diarrhea, headache, dizziness and fever (Rotter et al. 1996; Pestka and Smolinski 2005). Chronic exposure in animals modulates the immune system, affecting susceptibility to infections, and also causes growth faltering (Amuzie and Pestka 2010; Prelusky et al. 1997; Rotter et al. 1996). The mechanism of growth faltering remains unclear. At higher doses used in some animal models this may reflect DON induced food rejection; though at more moderate exposures it may reflect poor uptake and retention of nutrients due to DON induced damage and inflammation of the intestinal mucosa (Bouhet and Oswald 2005; Choi et al. 2009; Pinton et al. 2009).

DON has been shown to transfer to the fetus of pregnant sows (Goyarts et al. 2007; Tiemann et al. 2008), and exposure during pregnancy in sows has been linked to restrictions in both growth (Tiemann et al., 2008) and immune function (Jakovac-Strajn 2009). DON was subsequently observed in the liver and kidney of the fetus following exposure of the sow (Tiemann et al., 2008). DON restricts the growth of mice at doses lower than those restricting appetite (Amuzie and Pestka 2010); an effect associated with changes in growth hormone levels controlled by insulin like growth factors (IGF) (Voss 2010). IGFs are predominantly produced in the liver and thus DON induced liver toxicity may be one important determinant of growth and development in this species. DON was also 
demonstrated to be a teratogen in the Sprague-Dawley rat, based on anomalous development of the sternebrae (Collins et al., 2006).

Little is known about the level or effect of DON exposure during pregnancy in humans. Mycotoxin exposure from grain handling has been suggested (Garon et al., 2006; Turner et al., 2010a), and a relationship between grain farming and perinatal health in Norwegian farmers was reported (Kristensen et al. 1997); with the highest risk in seasons with poor quality harvest. In addition Fusarium toxins from grains have been proposed to induce labour at an early stage of pregnancy (reviewed by Pestka and Smolinski 2005). Given that DON can cross the placenta of animals (Goyarts et al. 2007; Tiemann et al. 2008) it is likely that in utero exposure to DON will occur in humans. The detoxification capacity of the fetus will not be fully developed, at a time of rapid growth and cell turnover (Myllynen et al., 2009); thus pregnancy may represent a critical window for DON exposure.

The use of a recently developed urinary biomarker for DON revealed that exposure within the UK was frequent (Turner et al. 2008a, 2008b, 2010b). The aim of the current study was to gain more insight into levels of maternal DON exposure during pregnancy. Born in Bradford $(\mathrm{BiB})$ is a large birth cohort study taking place in the United Kingdom recruiting pregnant women from the city of Bradford (Raynor 2008). The study is recruiting over 10,000 women and their children to allow investigation of a range of health related outcomes. Bradford has a large South Asian population mainly from the Mirpur region of Pakistan with over $40 \%$ of births in the city to women of Pakistani origin (Bradford District Infant Mortality Commission 2006). This survey assessed urinary DON biomarker levels in a subset of women taking part in $\mathrm{BiB}$.

The objective of this study was to provide the first biomarker assessment of DON exposure in pregnant women from the UK and to compare urinary biomarker assessment with dietary assessment based on food frequency questionnaires. To further examine relationships between the biomarker and dietary DON exposure with respect to demographic factors including ethnicity. 


\section{Materials and methods}

\section{Recruitment and sample collection}

Participants were pregnant women recruited into the BiB birth cohort study (Raynor 2008) and attending their final pre-assessment clinic for an elective caesarian section between $17^{\text {th }}$ January 2008 and $7^{\text {th }}$ May 2009. Women were sent information prior to their hospital visit about the study which was part of a EU funded project investigating xenobiotic exposures from the diet during pregnancy (Merlo et al. 2009). To assist with recruitment, collection of samples and completion of the demographic and dietary questionnaires, interviewers were available who could speak Mirpuri and Urdu, the main two non-English languages of South Asian origin.

All participants provided a urine sample either at the clinic, or one they had brought with them. These were stored at $-80^{\circ} \mathrm{C}$ until processed. They also completed questionnaires on their demographic characteristics and a 120 item Food Frequency Questionnaire (FFQ) asking about their average intakes over the previous 4-week period; participants were given the option to complete this after the appointment or take it home and return by post. The FFQ was developed specifically for the BiB sub cohort and aimed to permit characterisation of both traditional UK diets and British Asian diets. Questions were specifically included to permit the capture of food sources of DON, with a focus on the amount and type of cereals and cereal products.

All participants gave informed consent prior to study participation and ethical approval for the study was received from Bradford NHS Research Ethics Committee, UK.

\section{Defining ethnicity}

Participants self reported their ethnicity for the BiB study, including categories of 'Asian' and 'Asian British'. If ethnicity data was missing this was derived from the participants first and last name using the Nam Pehchan naming algorithm written to identify names of South Asian origin (Cummins et al. 1999; Macfarlane et al. 2007). South Asian ethnicity was assigned where either self reported or indicated using the Nam Pechan algorithm. 


\section{Urine analysis}

DON, ${ }^{13} \mathrm{C}_{15}$-DON, DOM-1, and type IX $\beta$-glucuronidase were obtained from Sigma-Aldrich (Poole, Dorset, UK). All other reagents were of HPLC grade. The urinary assay provides a combined measure of free DON and a DON-glucuronide (fD-DG), reported as urinary DON equivalents in $\mathrm{ng}$ per $\mathrm{ml}$ of urine (urinary DON $\mathrm{ng} / \mathrm{ml}$ ), as a biomarker of DON exposure. The assay uses ${ }^{13} \mathrm{C}_{15}$-DON as an internal standard (IS), immunoaffinity enrichment and LC-MS to quantification, as described in detail by Turner et al., (2008a; 2010a). DON was measured in batches of 20 samples alongside two blanks (phosphate buffered saline $\mathrm{pH} 7.2$ ) and two quality controls (QC) urines (blank urine spiked with 10ng DON/ml) per batch. DON was not detected in the blank controls and the mean QC concentration was $10.2 \mathrm{ng} / \mathrm{ml}, \mathrm{SD} 0.4 \mathrm{ng} / \mathrm{ml}$. The extracted samples were additionally measured for the de-epoxy metabolite of DON (DOM-1), according to the method of Turner et al., (2010a), using the extracts from above, but modified LC-MS parameters. For DOM-1 a blank and an eight point standard curve $(0.02$ - 100ng/ml) was used. No ${ }^{13} \mathrm{C}$ labeled DOM-1 was available as an IS. DOM-1 spiked urine at 0 (blank), 4 and $20 \mathrm{ng} / \mathrm{ml}$ were used as QCs and extracted as described above. DOM-1 was not observed in the blank, the mean QC concentrations were $3.3 \mathrm{ng} / \mathrm{ml}$ SD 0.3 and $17.3 \mathrm{ng} / \mathrm{ml}$ SD 0.6 , representing mean recoveries of $82.5 \%$ and $86.5 \%$ respectively. Given an average recovery of $84.5 \%$, the overall limit of detection was $0.06 \mathrm{ng} \mathrm{DOM}-1 / \mathrm{ml}$ urine.

Urinary creatinine analysis was conducted for all samples using an in-house micro-titre plate assay modified from the alkaline-picrate method described by Varley (1967). Urinary creatinine $(\mathrm{mg} / \mathrm{ml}$ urine) was used to adjust the $\mathrm{DON}$ concentration from $\mathrm{ng} / \mathrm{ml}$ urine to $\mathrm{ng} / \mathrm{mg}$ creatinine.

\section{Estimated DON intake from FFQs}

Seven cereal-containing food groups were identified for use in estimating DON exposure; (a) 'cereals high-DON' - breakfast cereals expected to have higher levels of DON contamination included high-fiber and wheat-containing cereals, (b) 'cereals low-DON' - cereals typically with lower levels of contamination included oats, rice-based, and non-wholegrain wheatbased products, (c) 'bread-white' - including pizza, chapatti (aka Indian flatbread) and naan, http://mc.manuscriptcentral.com/tfac Email: fac@tandf.co.uk 
(d) 'bread non-white', (e) a composite category of 'biscuits, cakes and crackers', (f) cerealbased savoury snacks, and (g) pasta. Data from a detailed survey of 377 individual UK food items carried out by the UK Food Standards Agency (UK FSA 2003) was used to obtain a mean DON contamination level for each of the seven food groups. This survey did not report the levels in pasta and so was supplemented with data on levels of DON contamination in pasta from European sources (Cirillo et al. 2003; Leblanc et al. 2005). No DON value was assigned to rice and rice dishes as the contaminant levels were extremely low in European and UK surveys (SCOOP 2003). Additionally, no foods made from maize were included in the FFQ as intake was expected to be low. In developing the estimates of mean DON contamination of the food group above, survey samples that had reported DON contamination levels below the limit of quantification (UK FSA 2003, Cirillo et al., 2003; Leblanc et al., 2005) were included and were assigned a value equal to half of the limit of detection $(5 \mu \mathrm{g} / \mathrm{kg})$. Values two or more standard deviations above the mean were excluded to remove the effect of a few, highly contaminated items skewing the exposure estimates. Total daily DON intake for an individual was calculated by multiplying the amount of each food category consumed by the estimated mean contamination value assigned to that food and summing the results over all categories. Mean DON contamination levels are presented in Table 1.

\section{Statistical analysis}

Differences in estimated intakes between the two defined ethnic groups (non-South Asian, South Asian) were measured using a t-test. Linear regression was used to investigate the relationship between creatinine adjusted levels of the DON biomarker and several explanatory factors including estimated DON dietary intake $(\mu \mathrm{g} /$ day), ethnicity, maternal age and maternal weight, which was taken when the mother attended her first pregnancy booking-in appointment. In these analyses both urinary biomarker level and estimated DON intake were natural log transformed to correct for skew in the data and to give a more interpretable relationship between the two variables. P-values to measure the influence of the term in the model were calculated using likelihood ratio tests. Firstly the four variables of 
interest were entered into the model separately and a final multivariate model was then applied including all variables which were significant in the univariate model at a level of $p=0.05$.

\section{Results}

\section{Participants}

During the study period a total of 338 women attended the pre-assessment clinic. Of these $175(52 \%)$ were recruited to be part of the sub-study and of these 86 provided a urine sample $(49 \%)$, one of whom later withdrew from the study. Reasons for not taking part included not wanting to be part of the main cohort study, language problems, illness and lack of time at the appointment visit. Overall 29/85 (34\%) women were classified as being South Asian in origin and 53 as non South Asian, and three women could not be classified. The average age of the women was 31 years (range: 21-44 years) and average weight of the women at their booking in appointment was $71 \mathrm{~kg}$ (range: $44-132 \mathrm{~kg}$ ).

\section{Urinary biomarker measurements}

Urinary (fD+DG) combined was detected in $85 / 85$ measured samples (geometric mean (GM): $10.3 \mathrm{ng} D O N / \mathrm{mg}$ creatinine, range: $0.5,116.7)$. Urinary DOM-1 was not detected in any of the samples. Overall the distribution of urinary DON was similar to that previously reported for predominantly white Caucasian UK women ( $n=156)$, Figure 1, GM 9.6ng/mg, range $0.5,43.4 \mathrm{ng} / \mathrm{mg}$ (Turner et al. 2008a); though it was notable that for the BiB sub-set there were $\sim 16 \%$ of samples with values greater than $35 \mathrm{ng} / \mathrm{mg}$ compared to only $1 \%$ for the earlier published survey. Mean urinary DON levels in the BiB samples were almost two fold higher in women classified as South Asian in origin (GM: 15.2ng/mg; 95\%Cl: $10.7,21.5)$ compared to non-South Asian women (GM 8.6ng/mg; 95\%Cl: 6.6, 11.8), $\mathrm{p}=0.02$ ).

\section{Estimated dietary intakes}

The mean predicted levels of DON contamination in the seven food categories ranged from $18.8 \mu \mathrm{g} / \mathrm{Kg}$ for 'cereal low-DON' to $93.9 \mu \mathrm{g} / \mathrm{Kg}$ for pasta, Table 1 ; thus consumption of any 
food items within these groups potentially contributed to DON exposure. A dietary FFQ was returned by $55 / 85(65 \%)$ of women with a urinary measure for DON. White bread was the major potential source of dietary DON in both South Asian (mean 154g/day; SD 149g/day) and non South Asian (58g/day; SD 46g/day), though with a significantly higher intake $(<0.001)$ in the former. Estimated intake from FFQ data gave an overall arithmetic mean DON intake of $10.1 \mu \mathrm{g} /$ day (SD: $8.9 \mu \mathrm{g} /$ day) and a median intake of $8.7 \mu \mathrm{g} /$ day (range: $1.4-$ $58.9 \mu \mathrm{g} /$ day). The major contributor to estimated DON intake was from white bread items (3.5 $\mu \mathrm{g} /$ day; $95 \% \mathrm{Cl}: 2.5,4.6 \mu \mathrm{g} / \mathrm{day})$, equal to $35.7 \%$; $95 \% \mathrm{Cl}: 29.6 \%-41.7 \%$ of the total estimated mean DON intake. The FFQ estimated intakes were significantly $(p=0.04)$ higher for South Asian (mean $13.7 \mu \mathrm{g} /$ day $(95 \% \mathrm{Cl}: 6.9,20.5 \mu \mathrm{g} /$ day) compared to non-South Asian (mean $8.4 \mu \mathrm{g} /$ day $(95 \% \mathrm{Cl}: 7.8,9.9 \mu \mathrm{g} /$ day) women (Table 1). This was mainly due to higher intakes of foods in the white bread group. Levels of most food items contained in this category were similar between women of different ethnicities apart from higher intake of chapattis, and consequently predicted higher mean DON intakes from this food item (mean $2.4 \mu \mathrm{g} /$ day $(95 \% \mathrm{Cl}: 1.2,3.7 \mu \mathrm{g} / \mathrm{day})$ for women of South Asian origin compared to women of non-South Asian origin $(0.2 \mu \mathrm{g} /$ day $(95 \% \mathrm{Cl}$ : 0, $0.4 \mu \mathrm{g} /$ day per day), $\mathrm{p}<0.001)$.

\section{Associations with biomarker intakes}

The results of the linear regression models are shown in Table 2. South Asian ethnicity and estimated DON intake (derived from the FFQ) were significant positive predictors of urinary DON levels using univariate analysis. Maternal booking weight and maternal age were nonsignificant. Therefore a final multivariate model was fitted including both ethnicity and estimated DON intake. When considering the adjusted $R^{2}$ value the model explained $22 \%$ of the variation in the DON urine levels, and both ethnicity $(p=0.01)$ and estimated DON intake $(p=0.02)$ contributed to the model. When cereal intake in grams per day (natural log transformed) was substituted for the estimated DON intake (as described above), cereal intake was not significantly associated with the urinary biomarker $(p=0.21)$.

\section{Conclusions}


Mycotoxins contaminate up to $25 \%$ of the worlds cereal crops (CAST 2003); however the potential health consequences of these exposures remains mostly poorly investigated, with perhaps the exception of the work on aflatoxins (IARC 2002). Mycotoxin contamination of cereals is heterogeneous, thus a major concern is accurate exposure assessment to inform epidemiological studies. In an attempt to meet this challenge a robust urinary DON exposure biomarker was recently demonstrated (Turner et al. 2008a, 2010b).

This study provides novel findings describing the level of a DON specific biomarker in a multi-ethnic sample of pregnant women living in the UK. Urinary DON was observed in all women, and the mean levels were similar to that reported in an earlier survey of 156 UK women of predominantly white Caucasian ethnicity (Turner et al. 2008b). In both surveys urinary DON levels were presented as a function of creatinine clearance, affording some adjustment for differences in timing of collections between the two studies. Pregnancy does not alter the 24 hour creatinine excretion compared to non pregnant individuals (Gallery et al., 1996). Turner et al., (2008b) previously suggested that a mean urinary level of about 9$10 \mathrm{ng} / \mathrm{mg}$ corresponded to an intake of roughly $20-25 \%$ of the recommended tolerable daily intake (rTDI) of $1000 \mathrm{ng} / \mathrm{Kg}$ bw/day (SCF 2002). The present study included three of the highest concentrations of urinary DON yet recorded $(92.5 \mathrm{ng} / \mathrm{mg}, 111.2 \mathrm{ng} / \mathrm{mg}$, and $116.7 \mathrm{ng} / \mathrm{mg})$; levels $9-11$ fold greater than the mean $(10.3 \mathrm{ng} / \mathrm{mg})$; and levels that would suggest that some of these women would be predicted to exceed the rTDI.

The de-epoxy metabolite, DOM-1, was not detected in this survey. DOM-1 is produced by intestinal microbiota rather than mammalian metabolism, and susceptibility to DON toxicity in part reflects the ability to produce DOM-1 (Yoshizawa et al. 1986); whilst data on the capacity in humans for this putative detoxification route are limited. De-epoxidase activity was not present in ten human fecal samples (Sundstøl Eriksen and Pettersson 2003); urinary DOM-1 was not observed in 22 UK adults, but was observed, albeit at modest levels compared to urinary DON, in 26/76 French farmers (Turner et al., 2010a). The observation in 
French farmers possibly reflects a modest acquisition of microbiota from cattle handling. Based on the general lack of detoxification by this route, and its strong association with being protective in species resistant to DON, these data suggest that humans may be particularly sensitive to DON. Insufficient urine was available to assess the ratio of free DON to the DON-glucuronide, another potentially important phenotypic measure of species susceptibility.

In the current study women of South Asian origin had a significantly higher level of both urinary DON and estimated DON intake based on the FFQ. Estimated DON intake based on typical levels of DON contamination and amounts of foods consumed improved models explaining the variation in the urinary biomarker compared to the more crude cereal intake. This is likely to be due to the wide variation in average DON contamination of cereal groups shown in Table 1. Bread intake was estimated to be the major determinant of intake, in line with earlier observations (SCOOP 2003; Turner et al. 2008b, 2009). It was notable that whilst white bread was estimated to be contaminated at lower levels than non white bread, its greater consumption within the study group, suggests that overall white bread provides an equal, or greater exposure risk than non-white bread at the population level, see Table 1. Estimated dietary DON intakes were higher in South Asian women in agreement with the biomarker data. This appears to be related to foods classified as breads, and in particular consumption patterns for chapattis. There is limited information on DON contamination of South Asian foods, and in our model of intake, chapattis were assigned levels typical of white bread. DON was previously detected in chapattis and naan bread obtained from specialist shops in the UK (Patel et al. 1996), though only four samples of each were measured. This limited sample size restricts the usefulness of any average or typical estimate of contamination, and would not be representative of levels in home cooked breads. Further measurements of DON in a greater range of traditional South Asian food items would clearly improve modeling of DON intake and provide important insights into the possibility of higher exposures in some sub-groups in the UK population. 
Limitations of the study include the relatively small size of the sample, and that the measurements were only carried out on women having elective caesarean sections; thus they may not be fully representative of all pregnant women. Whether this would be an indicator of differing dietary patterns during pregnancy is unclear. In conclusion, this is the first study to examine urinary DON during pregnancy of UK women. Urinary DON was frequently observed, and data reported here include the highest levels yet recorded. Urinary DOM-1 was not observed suggesting that humans may be particularly sensitive to DON exposure. South Asians had significantly higher levels of both the urinary biomarker and estimated DON intake. Growth faltering was recently highlighted as a likely consequence of DON exposure (Pestka and Smolinski 2005), and thus exposure during pregnancy may be particularly important. It is not clear whether pregnancy affects the toxicokinetics of DON, and this merits further examination. The possible health effects of DON in humans are still being investigated and this description of intake in a population that may be particularly vulnerable provides considerable impetus to conduct large scale epidemiological investigations. 


\section{Acknowledgments, grants and competing interests}

We are grateful to all the families who took part in this study, to the midwives for their help in recruiting them, the paediatricians and health visitors and to the Born in Bradford team which included interviewers, data managers, laboratory staff, clerical workers, research scientists, volunteers and managers. We also thank Susan Shires for technical assistance in this analysis. This work was co-financed by the EU Integrated Project NewGeneris, 6th Framework Programme, Priority 5: Food Quality and Safety (Contract no. FOOD-CT-2005016320). NewGeneris is the acronym of the project 'Newborns and Genotoxic exposure risks' http://www.newgeneris.org. CPW was supported by NIEHS, USA grant no. ES06052. 


\section{References}

Amuzie, C.J., Pestka, J.J., 2010. Suppression of Insulin-Like Growth Factor Acid-Labile Subunit Expression-A Novel Mechanism for Deoxynivalenol-Induced Growth Retardation. Toxicol. Sci. 113, 412-421.

Bouhet, S., Oswald, I.P., 2005. The effects of mycotoxins, fungal food contaminants, on the intestinal epithelial cell-derived innate immune response. Vet. Immunol. Immunopathol 108, 199-209.

Bradford District Infant Mortality Commission. 2006. Bradford and District Infant Mortality Commission - Final report. Available:

http://www.bradford.nhs.uk/ebm/BDIMC/Pages/TheReport.aspx [accessed 08/12/09].

Choi, H.J., Yang, H., Park, S.H., Moon, Y., 2009. HuR/ELAVL1 RNA binding protein modulates interleukin-8 induction by muco-active ribotoxin deoxynivalenol. Toxicol. Appl. Pharmacol. 240, 46-54.

Cirillo, T., Ritieni, A., Galvano, F., Cocchieri, R.A., 2003. Natural co-occurrence of deoxynivalenol and fumonisins B-1 and B-2 in Italian marketed foodstuffs. Food Addit.Contam. 20, 566-571.

Collins, T.F., Sprando, R.L., Black, T.N., Olejnik, N., Eppley, R.M., Hines, F.A., Rorie, J., Ruggles, D.I., (2006) Effects of deoxynivalenol (DON, vomitoxin) on in utero development in rats. Food Chem. Toxicol. 44, 747-57.

CAST (Council for Agricultural Science and Technology) 2003. Mycotoxins: Risks in Plant, Animal, and Human Systems. Task Force Report No. 139.

Cummins, C., Winter, H., Cheng, K.K., Maric, R., Silcocks, P., Varghese, C., 1999. An assessment of the Nam Pehchan computer program for the identification of names of south Asian ethnic origin. J. Public Health. Med. 21, 401-406.

Gallery EDM, Ross M, Gyory AZ (1996) 24-Hour Urinary creatinine excretion is not altered in human pregnancy. Hypertension Preg 15(2): 257-261. 
Garon, D., Richard, E., Sage, L., Bouchart, V., Pottier, D., Lebailly, P.. 2006. Mycoflora and multi-mycotoxin detection in corn silage: experimental study. J. Agric. Food. Chem. 54, 3479-3484.

Goyarts, T., Danicke, S., Brussow, K.P., Valenta, H., Ueberschar, K.H., Tiemann, U., 2007. On the transfer of the Fusarium toxins deoxynivalenol (DON) and zearalenone (ZON) from sows to their fetuses during days $35-70$ of gestation. Toxicol. Lett. $171,38-49$.

IARC. 2002. Some Traditional Herbal Medicines, Some Mycotoxins, Naphthalene and Styrene. In: IARC Monographs on the Evaluation of Carcinogenic Risks to Humans.

Jackson, L.S., Bullerman, L.B., 1999. Effect of processing on Fusarium mycotoxins. Adv. Exp. Med. Biol. 459, 243-261.

Jakovac-Strajn, B., Vengust, A., Pestevsek, U., 2009. Effects of a deoxynivalenol contaminated diet on the reproductive performance and immunoglobulin concentrations in pigs. Vet. Rec. $165,713-718$.

Kristensen, P., Irgens, L. M., Andersen, A., Bye, A.S., Sundheim, L., 1997. Gestational age, birth weight, and perinatal death among births to Norwegian farmers, 1967-1991. Am. J. Epidemiol. 146, 329-338.

Leblanc, J.C., Tard, A., Volatier, JILI, Vergerk P., 2005. Estimated dietary exposure to principal food mycotoxins from the first French Total Diet Study. Food Addit. Contam. 22, 652-672.

Macfarlane, G.J., Lunt, M., Palmer, B., Afzal, C., Silman, A.J., Esmail, A., 2007. Determining aspects of ethnicity amongst persons of South Asian origin: the use of a surnameclassification programme (Nam Pehchan). Public Health 121, 231-236.

Merlo, D.F., Wild, C.P., Kogevinas, M., Kyrtopoulos, S., Kleinjans, J., 2009. NewGeneris: a European study on maternal diet during pregnancy and child health. Cancer Epidemiol. Biomarkers Prev. 18, 5-10. 
Miller, J.D., 1995. Fungi and Mycotoxins in Grain - Implications for Stored-Product Research. J Stored Prod. Res. 31, 1-16.

Myllynen, P., Immonen, E., Kummu, M., Vakakangas, K., (2009) Developmental expression of drug metabolizing enzymes and transporter proteins in human placenta and fetal tissues. Expert Opin. Drug Metab. Toxicol. 5, 1483-99.

Patel, S., Hazel, C.M., Winterton, A.G.M., Mortby, E., 1996. Survey of ethnic foods for mycotoxins. Food Addit. Contam. 13, 833-841.

Pestka, J.J., Smolinski, A.T., 2005. Deoxynivalenol: toxicology and potential effects on humans. J. Toxicol. Environ. Health B Crit. Rev. 8, 39-69.

Pinton, P., Nougayrede, J.P., Del Rio, J.C., Moreno, C., Marin, D.E., Ferrier, L., Bracarense, A., Kolf-Clauw, M., Oswald, I.P., 2009. The food contaminant deoxynivalenol, decreases intestinal barrier permeability and reduces claudin expression. Toxicol. Appl. Pharmacol. 237, 41-48.

Prelusky, D.B., Rotter, B.A,. Thompson, B.K., Trenholm, H.L., 1997. Effect of the appetite stimulant cyproheptadine on deoxynivalenol-induced reductions in feed consumption and weight gain in the mouse. J. Environ. Sci. Health B 32, 429-448.

Raynor, P., 2008. Born in Bradford, a cohort study of babies born in Bradford, and their parents: protocol for the recruitment phase. BMC Public Health 8, 327-339.

Rotter, B.A., Prelusky, D.B., Pestka, J.J., 1996. Toxicology of deoxynivalenol (vomitoxin). J. Toxicol. Environ. Health B Crit Rev 48,, 1-34.

SCF (Scientific Committee on Food). 2002. Opinion of the Scientific Committee on Food on Fusarium toxins. Part 6: Group Evaluation of T-2 Toxin, HT-2 Toxin, Nivalenol and Deoxynivalenol: SCF/CS/CNTM/MYC/27 Final. Available: http://europa.eu.int/comm/food/ $\underline{\text { fs/sc/scf/out123 en.pdf }[a c c e s s e d ~} 15$ June 2007].

SCOOP (Scientific Cooperation). 2003. Collection of Occurrence Data of Fusarium toxins in Food and Assessment of Dietary Intake by the Population of EU Member States. SCOOP 
[accessed 15 June 2007]

Sundstøl Eriksen, G., Pettersson, H., 2003. Lack of de-epoxidation of type B trichothecenes in incubates with human faeces. Food Addit. Contam. 20:579-582.

Tiemann, U., Brussow, K.P., Danicke, S., Vanselow, J., 2008. Feeding of pregnant sows with mycotoxin-contaminated diets and their non-effect on foetal and maternal hepatic transcription of genes of the insulin-like growth factor system. Food Addit. Contam. Part A Chem. Anal. Control Expo. Risk. Assess. 25, 1365-1373.

Turner, P.C., Burley, V.J., Rothwell, J.A., White, K.L.M., Cade, J.E., Wild, C.P., 2008a. Dietary wheat reduction decreases the level of urinary deoxynivalenol in UK adults. J. Expo. Sci. Environ. Epidemiol. 18, 392-399.

Turner, P.C., Hopton, R.P., Lecluse, Y., White, K.L., Fisher, J., Lebailly, P., 2010a. Determinants of urinary deoxynivalenol and de-epoxy deoxynivalenol in male farmers from Normandy, France. J. Agri. Food Chem. 58, 5206-5212

Turner, P.C., Rothwell, J.A., White, K.L.M., Gong, Y., Cade, J.E., Wild, C.P., 2008b. Urinary deoxynivalenol is correlated with cereal intake in individuals from the United Kingdom. Environ. Health Perspect. 116, 21-25.

Turner, P.C., Taylor, E.F., White, K.L.M., Cade, J.E., Wild, C.P., 2009. A comparison of $24 \mathrm{~h}$ urinary deoxynivalenol with recent v. average cereal consumption for UK adults. Br. J. Nutr. $102,1276-1284$.

Turner, P.C., White, K.L.M., Burley, B.J., Hopton, P.H., Rajendram, A., Fisher, J., Cade, J.E., Wild, C.P., 2010b. A comparison of deoxynivalenol intake and urinary deoxynivalenol in UK adults. Biomarkers 15(6): 553-562.

UK Food Standards Agency. 2003. Survey of retail cereal products for tricothecenes and zearalenone 35/03.

Varley, H., 1967. Practical clinical biochemistry. London (NY): William Weimann Medical Books and Interscience Books, Inc. 
Voss, K.A., 2010. A New Perspective on Deoxynivalenol and Growth Suppression. Toxicol. Sci. 113, 281-283.

Yoshizawa, T., Cote, L.M., Swanson, S.P., Buck, W.B., 1986. Confirmation of DOM-1, a deepoxidation metabolite of deoxynivalenol in biological fluids of lactating cows. Agric.

Biol. Chem. 50, 227-229. 
Table 1 Estimated DON values used in the calculations of overall intakes\#

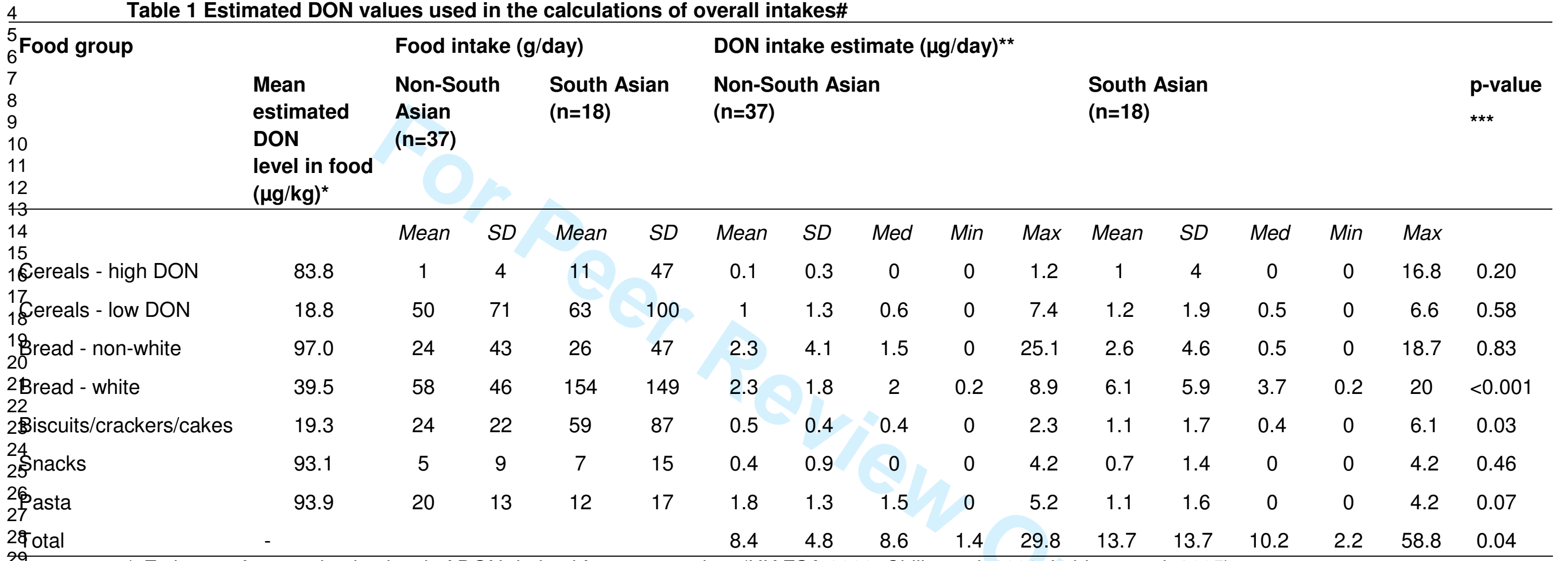

Estimate of contamination level of DON derived from survey data (UK FSA 2003; Cirillo et al. 2003; Leblanc et al. 2005)

${ }^{* *}$ DON intake estimated using the Food Frequency Questionnaire responses and mean DON levels

${ }^{* * * *} P$-value for $t$-test of comparing DON intake from each food group between Non-South Asians and South Asians

\# Data presented for non-consumers and consumers combined

Med - median value 
Table 2 Linear regression of natural log transformed DON biomarker values and four explanatory factors

\begin{tabular}{ll}
\hline Variable & $\begin{array}{l}\text { Number Coefficient 95\% Confidence Interval P-value } \\
\text { in the } \\
\text { analysis }\end{array}$ \\
\hline
\end{tabular}

Univariate Models

$\begin{array}{llllll}\text { Maternal Weight } & 76 & -0.002 & -0.016 & 0.012 & 0.77 \\ \text { Maternal Age } & 84 & 0.12 & -0.02 & 0.06 & 0.40 \\ \text { South Asian } & 85 & 0.54 & 0.08 & 0.99 & 0.02 \\ \text { FFQ DON }^{*} & 57 & 0.49 & 0.11 & 0.88 & 0.01\end{array}$

Multivariate Model 55 55

\begin{tabular}{lllll} 
Ethnicity & 0.69 & 0.16 & 1.22 & 0.01 \\
FFQ DON $^{\star}$ & 0.41 & 0.05 & 0.79 & 0.02 \\
\hline
\end{tabular}

${ }^{*}$ Natural log transformed

a Calculated using the likelihood ratio test 
Figure 1: Distribution of urinary DON (ng/mg) comparing BiB data with 156 UK women (modified from (Turner et al. 2008b)). Women from the latter survey were predominantly white Caucasian 


\section{Figure 1}

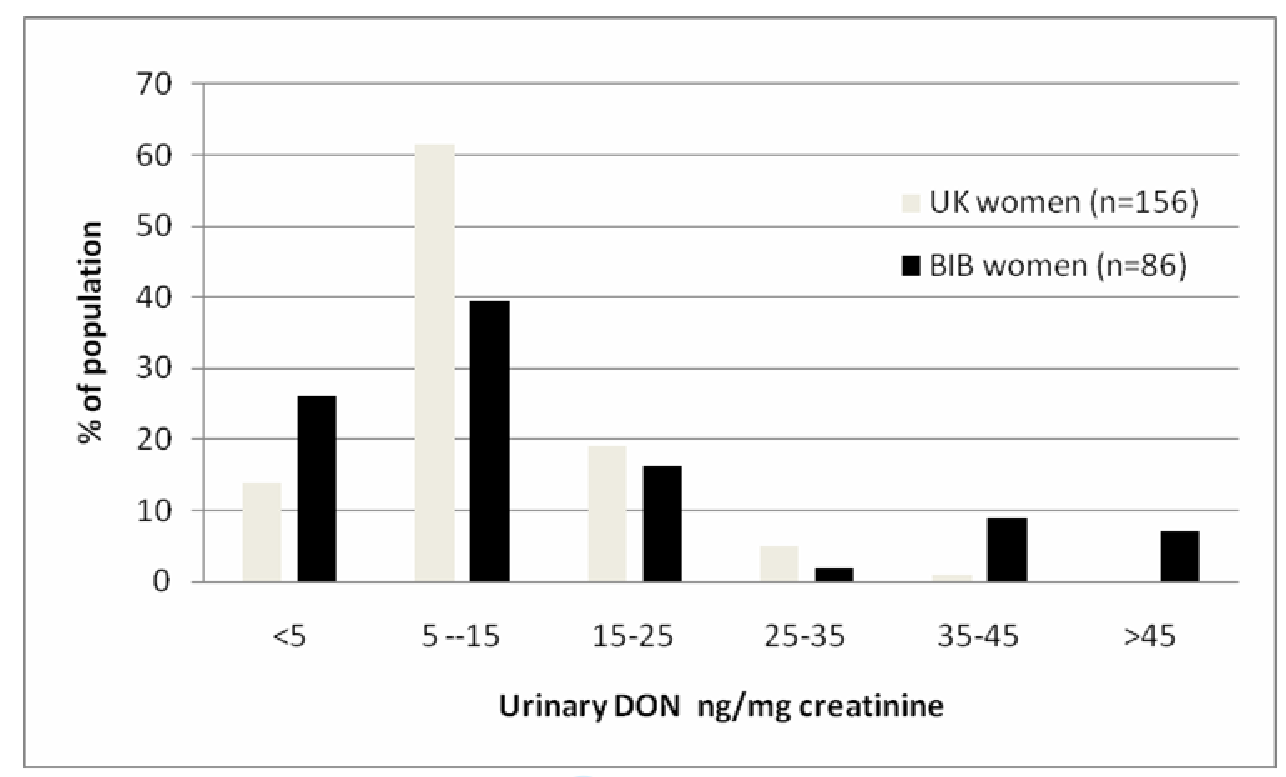

